\title{
How Well Does the Australian Aged Pension Provide Social Insurance?
}

Emily Dabbs and Cagri Kumru

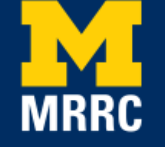

Project \#: UM15-14 


\title{
How Well Does the Australian Aged Pension Provide Social Insurance?
}

\author{
Emily Dabbs \\ Research School of Economics, Australian National University \\ Cagri Kumru \\ Research School of Economics, Australian National University
}

November 2015

\author{
Michigan Retirement Research Center \\ University of Michigan \\ P.O. Box 1248 \\ Ann Arbor, MI 48104 \\ www.mrrc.isr.umich.edu \\ (734) 615-0422
}

\section{Acknowledgements}

The research reported herein was performed pursuant to a grant from the U.S. Social Security Administration (SSA) funded as part of the Retirement Research Consortium through the University of Michigan Retirement Research Center (5 RRC08098401-07). The opinions and conclusions expressed are solely those of the author(s) and do not represent the opinions or policy of SSA or any agency of the Federal Government. Neither the United States Government nor any agency thereof, nor any of their employees, makes any warranty, express or implied, or assumes any legal liability or responsibility for the accuracy, completeness, or usefulness of the contents of this report. Reference herein to any specific commercial product, process or service by trade name, trademark, manufacturer, or otherwise does not necessarily constitute or imply endorsement, recommendation or favoring by the United States Government or any agency thereof.

\section{Regents of the University of Michigan}

Michael J. Behm, Grand Blanc; Mark J. Bernstein, Ann Arbor; Laurence B. Deitch, Bloomfield Hills; Shauna Ryder Diggs, Grosse Pointe; Denise Ilitch, Bingham Farms; Andrea Fischer Newman, Ann Arbor; Andrew C. Richner, Grosse Pointe Park; Katherine E. White, Ann Arbor; Mark S. Schlissel, ex officio 


\title{
How Well Does the Australian Aged Pension Provide Social Insurance?
}

\begin{abstract}
Social security plays an essential role in an economy, but if designed incorrectly can distort the labor supply and savings behavior of individuals in the economy. We explore how well the Australian means-tested pension system provides social insurance by calculating possible welfare gains from changing the settings in the current means-tested pension system. This work has been explored by other researchers both in Australia and in other pension-providing economies. However, most research ignores the fact that welfare gains can be found by reducing the cost of the program. To exclude these welfare costs, this paper fixes the cost of the system. We find that the means-tested pension system is welfare reducing, but does provide a better outcome than an equivalent-costing PAYG system. We also find that if the benefit amount is held constant, and hence the cost of the pension program is allowed to vary, a taper rate of 1.0 is optimal. However, once we fix this cost, a universal benefit scheme provides the best welfare outcome.
\end{abstract}

\section{Citation}

Dabbs, Emily and Cagri Kumru. 2015. "How Well Does the Australian Aged Pension Provide Social Insurance?” Ann Arbor, MI. University of Michigan Retirement Research Center (MRRC) Working Paper, WP 2016-339.

http://www.mrrc.isr.umich.edu/publications/papers/pdf/wp339.pdf 


\section{Introduction}

Social insurance plays an important role in the Australian economy, providing a form of insurance to people against risks such as illness, disability and longevity. In the 2014-15 financial year expenditure on social security and welfare is expected to account for over $30 \%$ of total government expenditure, with assistance for the aged a key driver of expenditure growth. ${ }^{1}$ Growth in expenditure on aged pension is a common theme across many countries, including the U.S., U.K. and Europe. For this reason, the provision of aged pension is a topic of much debate, with government policy experts and economists looking to reform current policies to ensure optimal provision of benefits to elderly individuals in society.

The Pay As You Go (PAYG) system and the means-tested system are two pension programmes analysed in the literature. PAYG is an intergenerational risk sharing system for social insurance whereby agents pay a specific social insurance tax and are provided with a benefit in times of retirement proportional to their average earnings. In times of a growing population and economic growth, this system works well as the new generation is funding the retired generation. But where an economy has an ageing population, with fewer working people funding more retirees, funding a PAYG system starts to become problematic and raises the question of efficient benefit allocation.

Due to the funding problem a PAYG system faces, means-tested pension systems have been the focus of many recent studies as this type of system reduces the fiscal burden through benefit targeting. This benefit targeting is achieved by providing payments to aged citizens based on their income and savings. The means-tested system is currently employed in many countries, including Australia.

The focus of our research is to explore how changes to the Australian means-tested pension system can provide welfare gains, using an open economy overlapping generations model. We first compare the current system and a stylised PAYG system against an economy where no pension system is in place, focusing on welfare gains and distributional effects. We then explore how changes to the current means-tested pension settings impact the labour supply and savings behaviour of individuals.

Possible welfare gains resulting from adjustments to social security systems have been explored quite extensively. In the U.S. context, where a PAYG system is in place, Auerbach \& Kotlikoff (1987) find that the PAYG system significantly reduces welfare. However, their paper does not take into account sources of uncertainty, which underlie the theory for government funded social insurance. Huggett \& Ventura (1999) and Imrohoroglu et. al (1995) extend on Auerbach and Kotlikoff's work by including life-span uncertainty and wage rate uncertainty. The results from their work indicate that, in the presence of incomplete annuity markets, the U.S. PAYG system can provide insurance benefits against longevity risk and income fluctuations.

Huggett \& Parra (2010) take a different approach to assessing the U.S. social security system. They first find the maximum welfare gains possible and then see how close the PAYG system and variations of this system come to reaching the maximum welfare level. Their results are similar to those found by Huggett \& Ventura (1999) and Imrohoroglu et. al (1995), in that whilst the PAYG

\footnotetext{
${ }^{1}$ This includes the following categories: Income support for seniors (age pension ), Residential and flexible care, Veterans' community care and support, Home support, Home care, National partnership payments - assistance to the aged, Mature age income support, Allowances - concessions and services for seniors, Ageing and service improvement, Workforce and quality, Access and information, and Other.
} 
system doesn't achieve the maximum welfare gains possible, it does provide significant welfare gains.

In recent years there has been a large amount of emerging literature on means-tested social insurance systems. Sefton \& van de Ven (2009) explored the U..K system with a means-tested framework and found that means-tested benefits are strictly preferred to a universal benefit structure. However, they also found that the means-tested system provides a disincentive for richer households to save but encouraged savings in poorer households. Kumru \& Piggott (2009) extended this work further by incorporating a second tier of the U.K. system, which represents a PAYG system, and explore optimal taper rates. They also find that a means-tested system is preferred to a universal pension system, and further, that a $100 \%$ income taper rate provides the highest level of welfare gains.

In the Australian context, Kudrna \& Woodland (2011) explore the impacts of different income taper rates on the savings and work behaviour of Australians and find, similar to Sefton \& van de Ven's (2009) results, that the current system provides a disincentive for older middle and higher income Australians to work. Tran \& Woodland (2014) extend on this work by exploring both changes to income taper rates and benefit payment rates. They find that, conditional on compulsory pension systems, when the maximum pension benefit is relatively low, an increase in the taper rate will always lead to a welfare gain. However, when maximum pension benefits are relatively more generous an increase in the benefit and taper rate will lead to welfare declines.

This paper builds on previous work, notably Kumru \& Piggott (2009), by adjusting both income taper rates and benefit payments simultaneously to fix the present value cost of the pension benefit system. This allows us to exclude welfare gains due solely to reduction in the cost of the system, and focus on identifying welfare gains due to reallocation between individuals.

We find that, similar to Auerbach \& Kotlikoff (1987) and Tran \& Woodland (2014), the meanstested system is welfare reducing. However, it provides higher welfare outcomes when compared to a PAYG style system. Significant differences in savings behaviour can be seen between poor and wealthy households under each system, with means-tested providing a disincentive for wealthy households to save. We also find that, similar to findings by Trans \& Woodland, the largest welfare gains within the means-tested system can be made with a taper rate of 1.0 as the insurance incentive offsets the distortionary effects on savings. However, when we fix the cost of the system

a universal benefit scheme provides the optimal outcome. This implies that when the cost of the system is allowed to vary, welfare gains are due to a lower costing system.

The paper is organised as follows. Section 2 outlines the model that will be used in the analysis. Section 3 discusses the parameterization of the model to the Australian economy. Results are presented in section 4 with a sensitivity analysis presented in section 5 , and section 6 concludes.

\section{The Model}

This section provides detail on the model used to analyse changes to the Australian pension programme. We use a simple partial equilibrium economy comprised of heterogeneous households, a production sector and a government sector. 


\subsection{Demographics and Endowments}

Our model economy is populated by overlapping generations who live up to a maximum of $J$ periods, with conditional probability of surviving from age $j$ to $j+1$ denoted by $v_{j}$. Every period $t$ a new generation is born with the population growing at an exogenous rate $n .^{2}$ There are constant cohort shares due to the constant growth rate and stationary demographics, which are defined as:

$$
\mu_{j}=\frac{\mu_{j-1} v_{j}}{1+n} \quad \text { for } \quad j=2,3,4, \ldots J
$$

with $\sum_{j=1}^{J} \mu_{j}=1$

Individuals face exogenous age-efficiency profiles, $\epsilon_{j}$, which represent changes to ability over time and are the same for all individuals. The productivity of an individual at a particular time period depends on not only on their age $j$, but they are also faced with idiosyncratic wage rate shocks $s_{j}$.

\section{$2.2 \quad$ Preferences}

In our model all individuals have identical preferences over consumption and leisure, which is denoted by the expected utility function with discount factor $\beta$ as follows:

$$
E\left[\sum_{j=1}^{J} \beta^{j}\left(\prod_{i=1}^{j} v_{i}\right) u\left(c_{j}, 1-l_{j}\right)\right]
$$

Each period individuals are endowed with 1 unit of labour, and they choose the amount of labour and leisure in that period, given by $l_{j}$ and $1-l_{j}$ respectively. Instantaneous utility is obtained through consumption and leisure, and defined as:

$$
u(c, 1-l)=\frac{c^{1-\rho}}{1-\rho}+\kappa \frac{(1-l)^{1-\varphi}}{1-\varphi}
$$

The coefficient of relative risk aversion is given by $\rho \in(0,+\infty)$ with the the inter-temporal elasticity of substitution of consumption given by $\frac{1}{\rho}$. The Frisch elasticity of leisure is given by $-\frac{1}{\varphi}$, with $\varphi \in(0,+\infty)$. $\kappa$ captures the dislike for work relative to enjoyment of consumption.

\subsection{Production sector}

The production sector consists of many perfectly competitive large firms, which is equivalent to one large firm that maximises profits. The representative firm produces output $Y$ at time $t$ using effective labour services $L$ and capital $K$ with exogenously given technology level A. The technology is represented by a Cobb-Douglas constant returns to scale production function:

$$
Y_{t}=A_{t} K_{t}^{\alpha} L_{t}^{1-\alpha}
$$

\footnotetext{
${ }^{2}$ The time notation is excluded from the rest of the model description for simplicity.
} 
The firm chooses capital and labour to maximise its profits, which can be expressed as:

$$
\max _{K, L}\left\{A K^{\alpha} L^{1-\alpha}-r K-w L\right\}
$$

\subsection{Government sector}

The government runs a pension programme and makes consumption expenditure. This section outlines the two pension programmes used in this model, as well as the taxation on consumption and income.

\section{Taxation}

The government collects tax on both income and consumption to finance its general expenditure and age pension. The consumption tax is set at rate $\tau^{c}$. Australia's income taxation system is progressive, whereby individuals in higher income bands are taxed more than those in lower income bands. It can be expressed as:

$$
T\left(y_{j}\right)=T_{k}+\tau_{k}\left(y_{j}-\overline{y_{k}}\right), \quad y_{j} \in\left[\overline{y_{k}}, y_{k+1}^{-}\right]
$$

where $\tau_{k}$ is the marginal tax rate, $T_{k}$ is the flat tax and $\overline{y_{k}}$ is the income threshold for the income bucket $k$. In the Australian context we have $T_{1}=0, \tau_{1}=0$ and $T_{k}=T_{k-1}+\tau_{k}\left(\overline{y_{k}}-y_{k-1}^{-}\right)$.

\section{Means-tested pension}

In the Australian benchmark model, the government runs a means-tested pension system. The benefit amount $b\left(y_{j}, a_{j}\right)$ is subject to two tests, an income test and an asset test, and can be written as:

$$
b^{m}\left(y_{j}, a_{j}\right)=\min \left\{b^{y}\left(y_{j}\right), b^{a}\left(a_{j}\right)\right\}
$$

where $b^{y}\left(y_{j}\right)$ is the income test pension and $b^{a}\left(a_{j}\right)$ is the asset test pension. So an individual receives the minimum of the two tests. Each test is subject to a threshold amount and is given by:

$$
b^{y}\left(y_{j}\right)=\left\{\begin{array}{lll}
b^{\max } & \text { if } & y_{j} \leq \overline{y_{1}} \\
b^{\max }-t_{y}\left(y_{j}-\overline{y_{1}}\right) & \text { if } \overline{y_{2}}<\overline{y_{j}}<\overline{y_{2}} \\
0 & \text { if } y_{j} \geq \overline{y_{2}}
\end{array}\right.
$$

where $\overline{y_{1}}$ and $\overline{y_{2}}=\overline{y_{1}}+b^{\max } / t_{y}$ are the income thresholds and $t_{y}$ is the taper rate for income, which is the rate at which the benefit is reduced for each dollar over $\overline{y_{1}}$.

$$
b^{a}\left(a_{j}\right)= \begin{cases}b^{\max } & \text { if } \quad a_{j} \leq \overline{a_{1}} \\ b^{\max }-t_{a}\left(a_{j}-\overline{a_{1}}\right) & \text { if } \overline{a_{2}}<\overline{a_{j}}<\overline{a_{2}} \\ 0 & \text { if } \quad a_{j} \geq \overline{a_{2}}\end{cases}
$$


where $\overline{a_{1}}$ and $\overline{a_{2}}=\overline{a_{1}}+b^{\max } / t_{a}$ are the asset thresholds and $t_{a}$ is the taper rate for assets, which is the rate at which the benefit is reduced for each dollar over $\overline{a_{1}}$.

\section{Pay-as-you-go (PAYG) pension}

The PAYG pension system collects a specific social security tax from workers during their work life, and then provides a payment that is proportional to the individuals average earnings. In this system, the social security tax rate is denoted $\tau_{s s}$ and the tax collected through the social security tax can be expressed as:

$$
T_{j}^{s}=\min \left\{\begin{array}{l}
\tau_{s s} l_{j} \epsilon_{j} s_{j} w \\
e_{\max }
\end{array}\right.
$$

where $e_{\max }$ is the maximum taxable level.

The benefit provided to retirees is denoted $b^{s}\left(x^{s}\right)$ where $x^{s}$ is an accounting variable, i.e. equally weighted earnings before retirement.

\subsection{An Individual's Decision Problem}

Individuals are heterogeneous with respect to state variables of age, working ability and asset holdings. An individual's state variables at age $j$ are denoted by $x_{j}=\left(e_{j}, a_{j}\right)$. Individuals realise their state $x_{j}$ and choose the optimal consumption $c_{j}$, leisure time $1-l_{j}$ (or working time $l_{j}$ ) and end of period asset holdings $a_{j+1}$ given wage and interest rates, government tax and pension policies, survival probabilities, and their working ability.

Individuals have three sources of income; returns from savings $r a_{j}$, effective labour earnings $l_{j} \epsilon_{j} s_{j} w$, and possible pension payment $b_{j}$. Therefore their income can be expressed as:

$$
y_{j}=\left\{\begin{array}{l}
r a_{j}+l_{j} \epsilon_{j} s_{j} w \text { if } j<j * \\
r a_{j}+b_{j}(x) \text { if } j \geq j *
\end{array}\right.
$$

From this we can express an individual's growth-adjusted budget constraint as:

$$
\left\{\begin{array}{ll}
c_{j}+(1+g) a_{j+1} \leq(1+r) a_{j}+\left(1-\tau_{s}-\tau_{p}\right) l_{j} \epsilon_{j} s_{j} w-\tau\left(y_{i}\right) & \text { when } j<j * \\
c_{j}+(1+g) a_{j+1} \leq(1+r) a_{j}+b_{j}+b_{j}^{\prime}(x)-\tau\left(y_{i}\right) & \text { when } j \geq j * \\
c_{j} \leq(1+r) a_{j}+b_{j}(x)+b_{j}^{\prime}(x)-\tau\left(y_{i}\right) & \text { when } j=J
\end{array}\right\}
$$

and we assume that individuals cannot borrow against future income:

$$
a_{j} \geq 0, \forall j
$$


Hence, an individual's decision problem in our model can be written as the dynamic programming problem below, where $V_{j}$ is the value function of the individual at age $j$ and $x^{\prime}$ is the next period state vector.

$$
V_{j}(x)=\max _{c_{j}, l_{j}}\left\{u\left(c_{j}, l_{j}\right)+\beta v_{j+1} E V_{j+1}\left(x^{\prime}\right)\right\}
$$

subject to equations 11 and 12 .

\subsection{Equilibrium}

Our equilibrium definition follows Auerbach \& Kotlikoff (1987), Imrohoroglu et. al (1995), and Kumru \& Piggott (2009).

Given government policy settings for taxation and the pension system, the constant population growth rate, and exogenous interest rate, a stationary equilibrium is such that:

1. a collection of individuals' decisions $\left\{c_{j}(\cdot), l_{j}(\cdot), a_{j+1}(\cdot)\right\}_{j=1}^{J}$ solve the individual decision problem (13) subject to constraints (11) and (12)

2. age dependent distributions of individuals are calculated as:

$$
\Lambda_{j+1}(x)=s_{s} \quad\left(s_{j+1}, s_{j}\right) \int_{X} d \Lambda_{j}
$$

where $\prod\left(s_{j+1}, s_{j}\right)$ is the transition matrix for the shocks. $\Lambda_{1}(x)$ is given.

3. the firm chooses labour and capital inputs to solve the maximisation problem (5)

4. the lump-sum bequest transfer $(\Omega)$ is equal to the sum of accidental bequests:

$$
\Omega={ }_{j=1}^{J} \mu_{j} \int_{X}\left(1-v_{j+1}(z)\right) a_{j}(x) d \Lambda_{j}
$$

5. aggregate capital $(K)$, labour $(L)$ and consumption $(C)$ is derived from individuals' behaviour

$$
\begin{gathered}
K={ }_{j=1}^{J} \mu_{j} \int_{X} a_{j}(x) d \Lambda_{j} \\
L={ }_{j=1}^{J} \mu_{j} \int_{X} l_{j}(x) d \Lambda_{j} \\
C={ }_{j=1}^{J} \mu_{j} \int_{X} c_{j}(x) d \Lambda_{j}
\end{gathered}
$$


6. age pension programmes are self-financing:

$$
\begin{aligned}
& { }_{j=j *}^{J} \mu_{j} b^{m}(x) d \Lambda_{j}=\tau^{m}{ }_{j=1}^{j *-1} \mu_{j} y_{j}(x) d \Lambda_{j} \\
& { }_{j=j *}^{J} \mu_{j} b^{s s}(x) d \Lambda_{j}=\tau^{s s}{ }_{j=1}^{j *-1} \mu_{j}{ }_{X} \min \left\{y_{j}(x), y_{\max }\right\} d \Lambda_{j}
\end{aligned}
$$

7. the Government budget constraint is satisfied at every period:

$$
T^{i n c}+\Omega+\tau_{c} C+=G
$$

8. goods market clears:

$$
C+(1+g)(1+n) K+G=Y+(1-\delta) K
$$

\section{Calibration}

This section details the parameters used in our model. We calibrate the benchmark model to the Australian economy. The key parameters are detailed in Table 1.

Table 1: Parameters

\begin{tabular}{cccc}
\hline \hline Demographics & Parameters & Model & Observation / Comment / Source \\
& Initial age & $j=1$ & Age 21 \\
& Maximum age & $j=65$ & Age 85 \\
Retirement age & $j *=55$ & Age 65 \\
& Annual Population Growth & $n=0.012$ & ABS data \\
& Survival probabilities & $v_{j}$ & ABS data \\
& Age efficiency profile & $\epsilon_{j}$ & HILDA data \\
\hline Preferences & & & \\
& Annual discount factor & $\beta=0.99$ & Match Australian saving behaviour \\
& Risk adversion parameter & $\rho=2$ & Tran \& Woodland (2011) \\
& Frisch elasticity & $\gamma=0.35$ & Buddelmeyer et. al (2007) \\
\hline Production & Capital share of GDP & $\alpha=0.4$ & Tran \& Woodland (2014) \\
& Interest rate & $r=0.0495$ & Average10 year Treasury bond \\
\hline Government & Consumption tax & $G=0.14$ & Tran \& Woodland (2014) \\
& Income taxes & $\tau_{j}^{c}, T_{j}, \overline{y_{j}}$ & Endogenously determined \\
& Government consumption & 2014-15 tax schedules \\
& Means-tested pension & $b^{m a x}, t_{y}, t_{a}, \overline{y_{1}}, \overline{a_{1}}$ & 2014-15 pension rules \\
& PAYG pension & Huggett \& Parra (2010)
\end{tabular}

\section{Demographics}

Our model assumes individuals are born, or become economically active, at age $21(j=1)$ and live up to a maximum age of $85(j=65)$. The population growth rate is set to $1.2 \%$ which is the 
Australian average over the last 10 years. The conditional survival probabilities $\left(v_{j}\right)$ of individuals are estimated using ABS data on death rates.

The age efficiency profiles $\left(\epsilon_{j}\right)$ correspond to hourly wage rates by age. We have estimated the Australian age efficiency profile using the data from the Household, Income and Labour Dynamics in Australia (HILDA) survey $^{3}$, similar to Tran \& Woodland (2014).

We estimate the idiosyncratic wage rate shocks using a five-point discrete Markov chain process as described by Tauchen \& Hussey (1991). Similar to Cho \& Sane (2011) we use the Gini coefficient as a measure of the variance, which is 0.34 taken from Greenville et. al. (2013). The shocks are calculated as $s_{k}=\{0.2069,0.4133,0.7721,1.4424,2.8819\}$ and the probabilities for each shock are calculated as $p_{k}=\{0.0988,0.2418,0.3188,0.2418,0.0988\}$

\section{Preferences}

We set $\rho=2$ which is a standard assumption for Australia. We then set $\kappa=1$ to normalise to unity. We calibrate $\varphi$ to match the Frisch elasticity of $\gamma=0.35$. We use $\beta=0.99$ to match the Australian savings behaviour, which is also used by Tran \& Woodland (2014).

\section{Production sector}

We use the capital share of GDP $\alpha=0.4$ as calculated in Tran \& Woodland (2014). As Australia is a small economy, we use a partial equilibrium model where factor prices are set exogenously. We set the interest rate $r=0.0495$ which is the average of Australian Treasury bonds over the last 10 years.

\section{Government sector}

Figure 1: Marginal Tax Rates

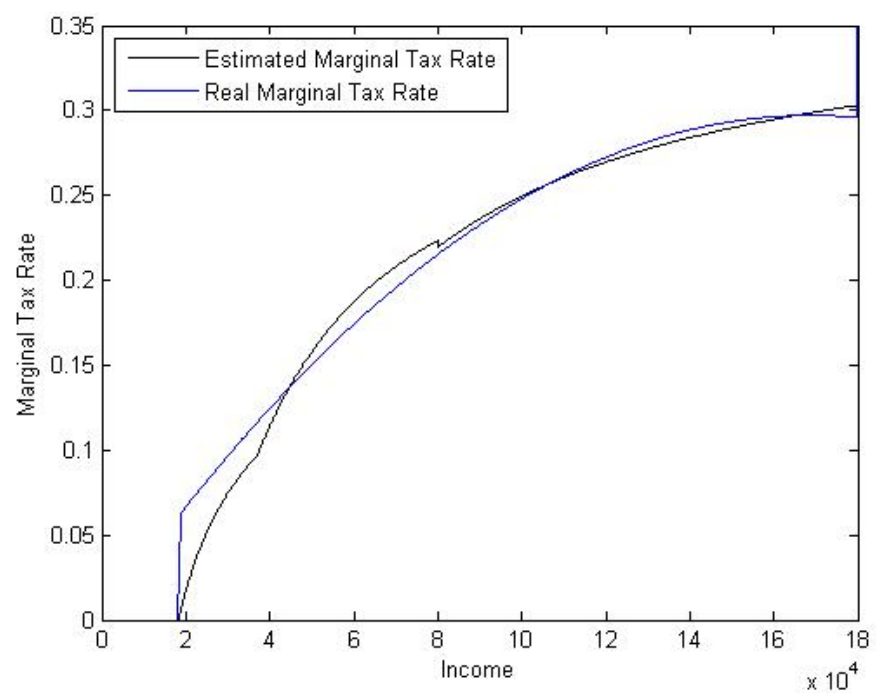

The consumption tax rate adjusted endogenously within the model to ensure the government budget is balanced. We use a quadratic function to approximate the marginal tax rates individuals

\footnotetext{
${ }^{3}$ HILDA is a longitudinal household survey that collects data on income, work, and family / household formation. Similar to Tran \& Woodland (2011) we use data from the first 7 waves of the survey for our age efficiency profiles.
} 
face, similar to that used by Kumru \& Piggott (2009) and Huggett \& Parra (2010). The actual marginal tax rates versus the estimated marginal tax rates are shown in Figure 1, which verifies that the quadratic function matches real marginal tax rates fairly closely.

We use the means-tested pension rates as detailed by the Department of Human Services for 2014-15. This includes a taper rate on income of $t_{y}=0.5$, a benefit reduction rate on assets of $t_{a}=0.0015$, an income threshold of $\overline{y_{1}}=\$ 4,160$ per year, an asset threshold of $\overline{a_{1}}=\$ 348,500$ and a benefit payment of $\$ 14,846$ per year. As our model does not adequately capture homeownership, we use the asset threshold for individuals who do not have a family home.

To compare the Australian means-tested pension system to a PAYG system, we use Huggett \& Parra (2010) benefit payment parameters for the PAYG system. This is expressed as a benefit payment function in Figure 2. We set the social security tax such that the net present value of the system matches the benchmark Australian means-tested system, in this case $\tau_{s s}=21.8 \%$.

Figure 2: PAYG Benefit Function

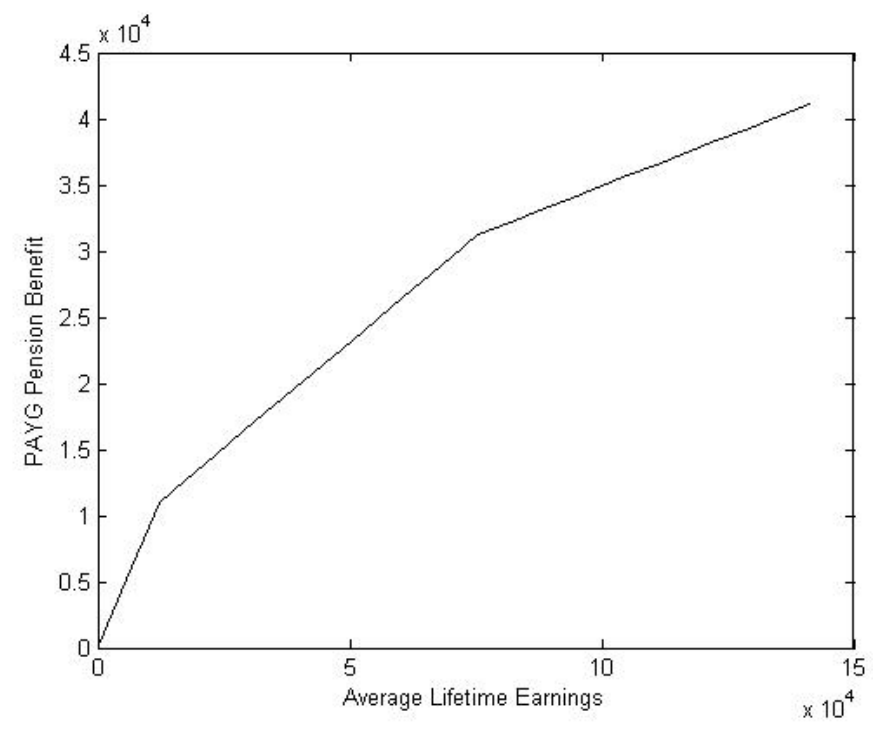

\section{Simulation Results}

This section first compares our benchmark model to the current Australian economy before exploring different policy changes. When discussing policy changes we focus on comparing means-tested pension system and PAYG pension systems before considering changes to taper rates and pension payment rates, holding the cost of the programme constant.

\subsection{Benchmark Model}

Before considering changes to the Australian means-tested pension system, we first examine key outputs of our model to see that it matches features of the Australian economy. 


\section{Asset profile ${ }^{4}$}

In order to compare our model output to real Australian data, we use the HILDA survey results on assets and wealth distribution. As can be seen in Figure 3, our model generates the same lifecycle asset accumulation whereby individuals accumulate assets early in their life before drawing down on them during retirement. We can see that assets are lower earlier in life, starting at 0 when $j=1$, as we constrain our model such that individuals start their working life with no assets. We can also see that peak savings, while at the same stage of life in both sets of data, is much higher in the real data compared to our model output. Housing is often cited as a key incentive for saving in the Australian context, and while excluded from the data there may be flow on to other savings behaviour. So this difference in peak savings may be attributed to the fact that our model doesn't include housing.

Figure 3: Asset Profile

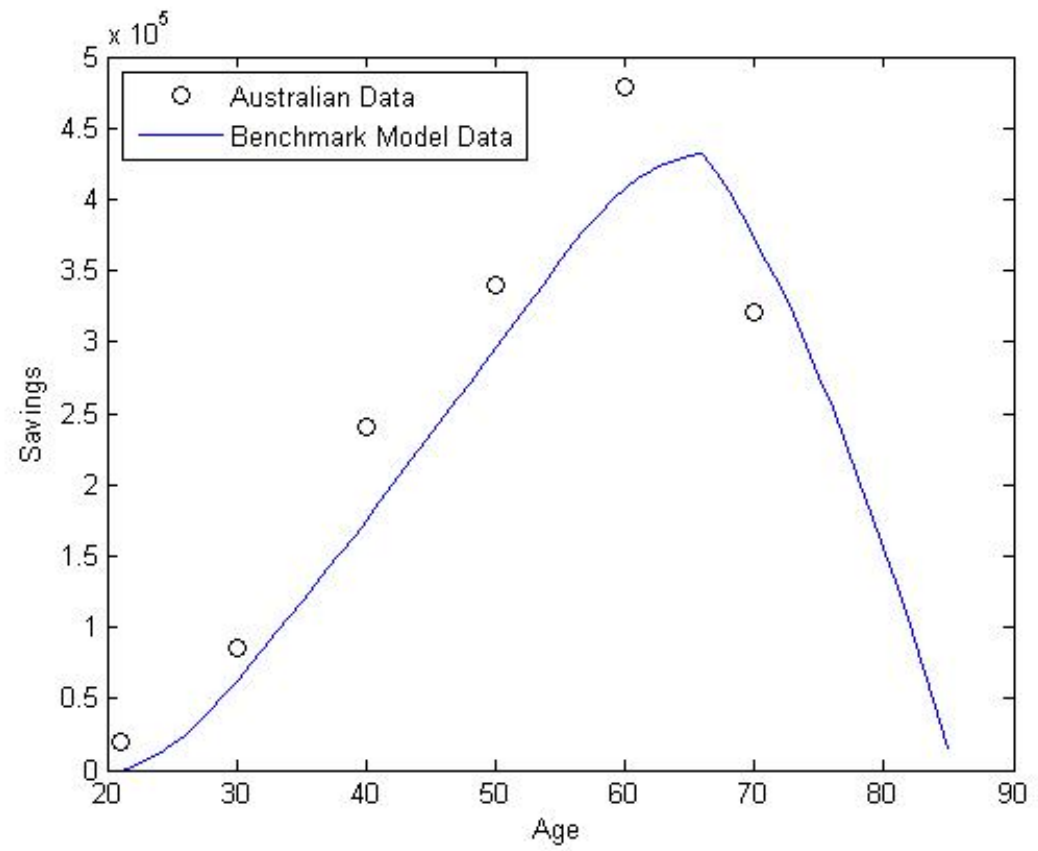

\section{Labour market}

Our model matches the life cycle labour supply behaviour of individuals fairly well, as shown in Figure 4. A notable difference being that younger individuals work more than the observed data shows. This is primarily due to the assumption in our model that individuals enter their working life with no assets and cannot borrow. We also make the retirement decision exogenous in our modeling, meaning that individuals leave the workforce at 65 .

\subsection{Comparison of Pension Systems}

In this section we compare the benchmark model and a stylised PAYG pension system with the Australian economy without a pension system in place. We focus on welfare differences and explore

\footnotetext{
${ }^{4}$ Assets in our model do not include compulsory superannuation or housing
} 
Figure 4: Labour Profile

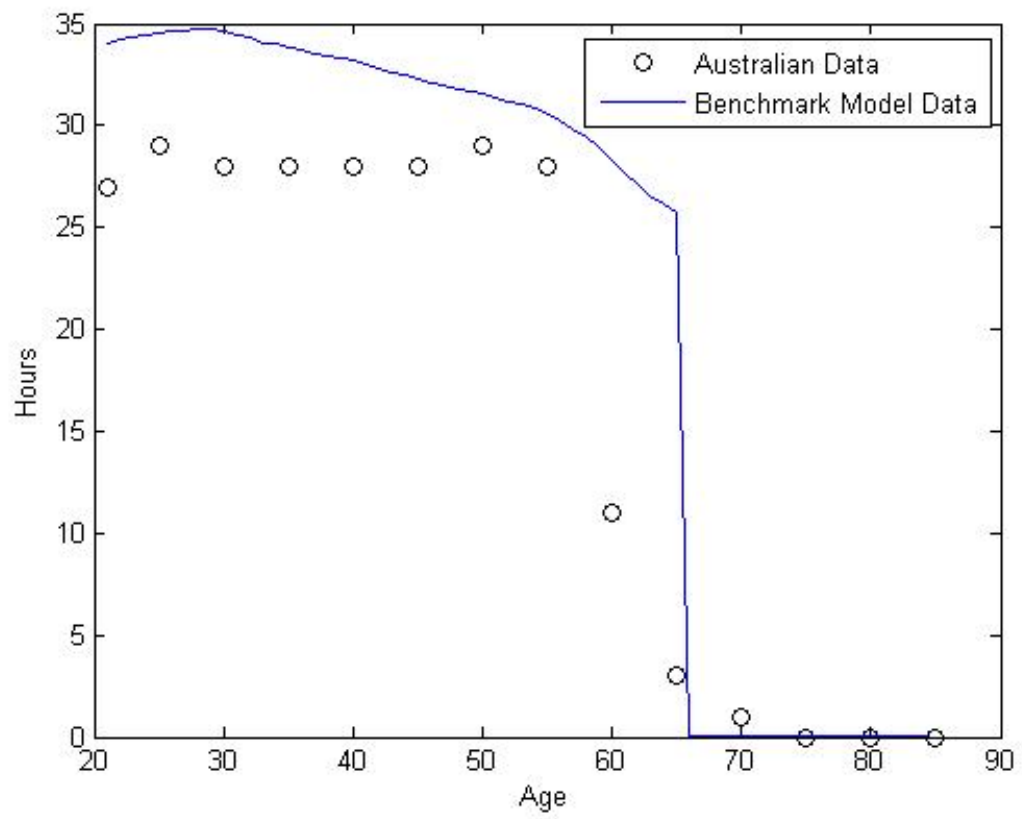

changes in savings and labour supply behaviour.

A pension system has two opposing impacts on individuals behaviour; it provides a form of risk-sharing but also distorts individuals labour supply and savings behaviour. We use the results in Table 2 to assess which of these is the dominant force in the PAYG pension system, means-tested pension system and an economy without a pension system.

To compare the models in terms of welfare we compute the consumption equivalent variation (CEV), which is a standard method following on from Conesa et. al (2009) and Kumru \& Thanopoulos $(2011)^{5}$. We use the model with no pension as the baseline for analysis in this section, meaning a positive CEV indicates a welfare gain compared to the model with no pension and a negative CEV indicates a welfare loss compared to the model with no pension. We also use the model with no pension as the baseline model for comparing relative changes in savings and labour supply.

Table 2: Results from Comparison of Pension Systems

\begin{tabular}{ccccc}
\hline \hline System & Cost of Pension System & CEV $(\%)$ & Aggregate Labour & Aggregate Savings \\
\hline No pension & NA & 0 & 100 & 100 \\
PAYG & -1.54 & -23 & 117.2 & 60.1 \\
Means-tested & -1.54 & -22 & 116.5 & 61.1 \\
\hline
\end{tabular}

As shown in Table 2, both pension systems are welfare reducing. Individuals in both the means-

\footnotetext{
${ }^{5}$ As described in Kumru \& Thanpoulos (2011) CEV $=\left[\frac{V\left(x_{0}^{*}\right)}{V\left(x_{1}^{*}\right)}\right]^{1 /(1-\rho)}-1$, where $x_{0}^{*}$ is the benchmark model allocation and $x_{1}^{*}$ is the new system allocation
} 
tested and PAYG system have much lower savings over their life-span than under the model with no pension system. This aligns with the results from Tran \& Woodland (2014), Auerbach \& Kotlikoff (1987), and Imrohoroglu et. al (1995), which consistently find that pension systems are welfare reducing due to the dominant effect of incentive distortion. Figure 5 shows this distortion clearly through the savings behaviour of individuals under each of the systems.

Figure 5: Average Asset Profiles

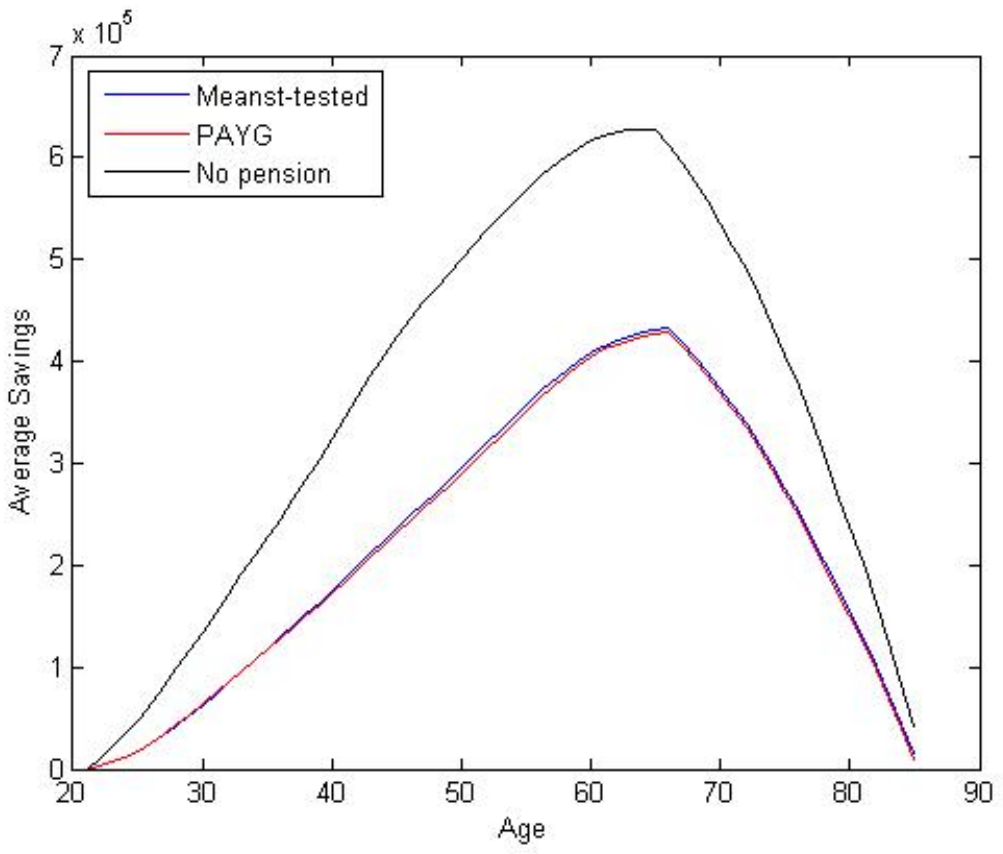

Now we take a closer look at the differences between the two pension systems. As can be seen from Table 2, a PAYG system has a lower CEV (-23\%) when compared to a means-tested system $(-22 \%)$. This provides an additional layer of analysis to show that the averse incentive effects are marginally smaller under the means-tested system compared with the PAYG system. To fully understand the differences between the two systems, we compare the different impacts on the poor and wealthy in the economy.

Let us first consider the lowest earners in the system, and examine their savings and labour supply behaviour. As can be seen by Figure 6, lowest earners do not change their savings or labour supply behaviour between the two systems. This is because they have no incentive to lower savings under a means-tested system, given they are already receiving the largest benefit. In the case of a PAYG system, they cannot increase their labour supply sufficiently to increase their benefit payment in retirement, hence they have lower utility under a PAYG system.

We can see in Figure 7 that the highest earners accumulate assets earlier in life in a PAYG system, reaching a much higher peak of savings than under a means-tested system. The disincentive to save under a means-tested system for wealthy individuals is due to the fact that their benefit in retirement reduces if their savings levels are too high. There is no such disincentive under a PAYG system, hence the higher savings and higher utility for wealthy individuals in a PAYG system. 
Figure 6: Labour Supply and Savings Behaviour of Lowest Earners
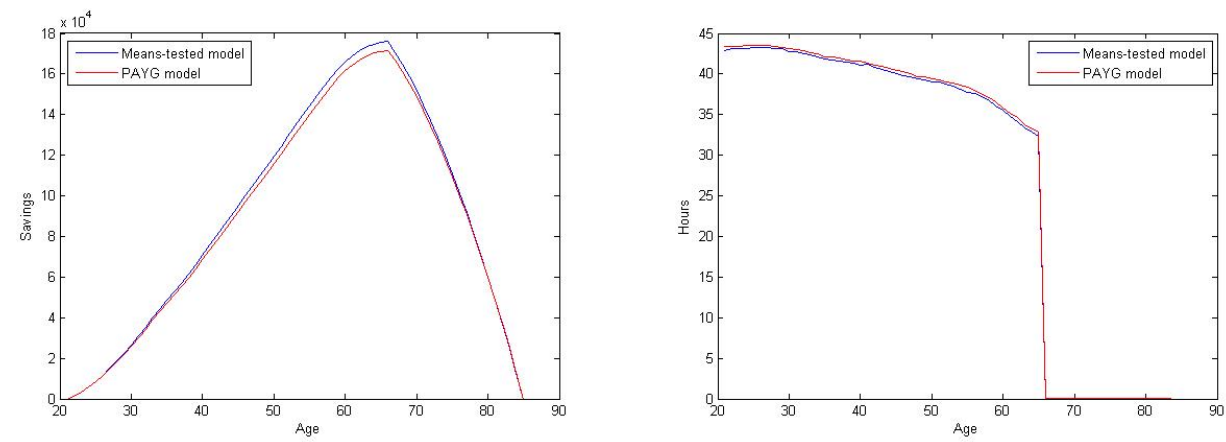

Figure 7: Labour Supply and Savings Behaviour of Highest Earners
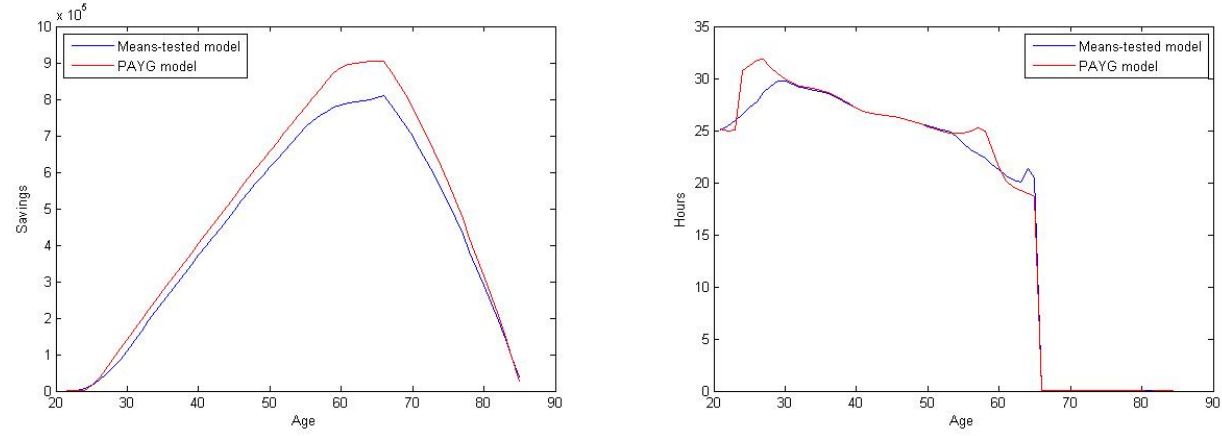

We conclude that while the means-tested pension system is welfare reducing, the reduction in welfare is lower than that under the PAYG pension system. The two systems have very different impacts on the savings behaviour of individuals, with the means-tested system providing a disincentive for wealthier individuals to save.

\subsection{Changes to Means-tested Policy}

In this section we explore changes to the income taper rate in the means-tested system. By varying the taper rate we are changing the effective marginal tax on income in retirement, with a higher taper rate increasing the effective marginal tax. Given savings are the single source of income in retirements, by changing the taper rate we expect to see changes to savings behaviour. We first explore these effects in a model with varying cost, before examining how imposing constant cost of the programme changes the results. In this section we use the benchmark model as the baseline for examining welfare gains with $\mathrm{CEV}$ and relative changes to savings and labour.

\section{Variable system cost}

We first simulate a number of alternative model economies where we vary the taper rate in the means-tested pension holding the income threshold, benefit payment, and asset testing constant. A different taper rate has two main effects; it changes the value of the benefit paid to retirees and simultaneously changes the number of retirees who receive benefit payments. Table 3 reports the welfare effects as well as the main aggregate variables we are interested in.

The results reported in Table 3 indicate that in our model economy a taper rate of 1.0 provides 
Table 3: Results from Changes to the Taper Rate

\begin{tabular}{cccccc}
\hline \hline Taper Rate & Maximum Benefit & Cost of Pension System & CEV & Savings & Labour \\
\hline 0.0 & 15,000 & -1.94 & -7.550 & 92.4 & 98.8 \\
0.1 & 15,000 & -1.85 & -4.429 & 96.1 & 101.1 \\
0.2 & 15,000 & -1.78 & -3.027 & 97.7 & 100.7 \\
0.3 & 15,000 & -1.71 & -3.004 & 96.8 & 100.8 \\
0.4 & 15,000 & -1.63 & 0.390 & 100.9 & 99.9 \\
0.5 & 15,000 & -1.54 & 0.000 & 100.0 & 100.0 \\
0.6 & 15,000 & -1.44 & 4.091 & 104.8 & 99.0 \\
0.7 & 15,000 & -1.38 & 5.130 & 105.9 & 98.7 \\
0.8 & 15,000 & -1.29 & 7.325 & 108.5 & 98.2 \\
0.9 & 15,000 & -1.22 & 8.599 & 109.6 & 97.9 \\
1.0 & 15,000 & -1.17 & 9.597 & 110.6 & 97.7 \\
\hline
\end{tabular}

the greatest welfare gain, similar to the conclusion from Kumru \& Piggott (2009) and Tran \& Woodland (2014). At this taper rate, we are maximising the risk-sharing mechanism while minimising the distortionary impact on savings behaviour.

We can see the distortionary effects on savings increase as the taper rate decreases due to fact that individuals have a lower incentive to save for their retirement. As the taper rate decreases, more individuals become eligible for the pension programme, meaning they do not need to save as much for their retirement. Under a universal benefit (taper rate $=0.0$ ), everyone receives a benefit regardless of their income, meaning even the wealthiest individuals in the economy can reduce their savings and still maintain their consumption in retirement.

The impact on labour supply behaviour is much less significant, with a lower taper rate resulting in higher labour supply behaviour. Again, this result is due to the fact that a higher taper rate results in more individuals lowering their labour, and hence savings and income in retirement, to ensure their eligibility for the pension system.

The results in Table 3 show that the cost of the system increases as the taper rate decreases, as individuals who received very little or no pension benefit now receive a higher payment. This means our results cannot indicate if the welfare gains due to higher taper rates are due to an optimal distribution of benefits or simply due to a lower costing pension programme. To explore this further, we fix the cost of the programme by varying the benefit amount, and compare the changes in welfare and savings behaviour.

\section{Constant system cost}

We now simulate a number of alternative model economies where we vary the taper rate and benefit amount in the means-tested pension, holding the cost of the programme constant. Again we hold the income threshold and asset testing constant. By keeping the cost of the programme constant we can ensure that changes in welfare are solely attributed to the distribution of benefit payments in the economy and exclude any welfare changes due to a change in the cost of the pension system.

The results in Table 4 show that when the cost of the system is held constant, the optimal 
Table 4: Results from Changes to the Taper Rate with Constant Cost

\begin{tabular}{cccccc}
\hline \hline Taper Rate & Maximum Benefit & Cost of Pension System & CEV & Savings & Labour \\
\hline 0.0 & 9,000 & -1.54 & 0.697 & 100.6 & 99.8 \\
0.1 & 10,000 & -1.54 & 0.496 & 100.2 & 99.9 \\
0.2 & 12,000 & -1.54 & 0.483 & 100.1 & 99.9 \\
0.3 & 13,000 & -1.54 & 0.363 & 100.1 & 99.9 \\
0.4 & 14,000 & -1.54 & 0.183 & 99.8 & 100.0 \\
0.5 & 15,000 & -1.54 & 0.000 & 100.0 & 100.0 \\
0.6 & 16,000 & -1.54 & -0.007 & 100.0 & 100.0 \\
0.7 & 17,000 & -1.54 & -0.096 & 99.9 & 100.1 \\
0.8 & 17,000 & -1.54 & -0.126 & 99.8 & 100.1 \\
0.9 & 18,000 & -1.54 & -0.191 & 99.7 & 100.1 \\
1.0 & 19,000 & -1.54 & -0.292 & 99.6 & 100.1 \\
\hline
\end{tabular}

taper rate is 0.0 , a universal benefit scheme. This directly opposes the results from the variable cost system, indicating that the driver for welfare gains under a variable cost pension programme is lower cost, and hence lower tax on individuals.

Under the fixed cost economies, changes in the taper rate also produce opposing results for savings and labour supply behaviour. As the taper rate and benefit payment increase, the incentive to lower savings increases as individuals reduce their income in retirement to become eligible for the pension programme.

From this analysis, we conclude that under a system with a fixed benefit, a taper rate of 1.0 is preferred to all other taper rates. Lower taper rates distort the savings behaviour of individuals in the economy through the higher tax rate needed to fund the pension programme. However, when we hold the cost of the system the same, we find that a universal benefit is preferred. As the benefit payment is lower, the distortionay effects on savings behaviour are minimised. This is an important result as it highlights that the distortionary effects of changes to taper rates within a means-tested pension system are due to changes in tax rates on individuals. Changes to the taper rate under a fixed cost pension system produce the opposite affect, with a universal benefit providing the best welfare outcome. Again, this indicates that the results from a variable cost pension programme are driven by the cost of the system, rather than the distribution of benefits.

\section{Sensitivity Analysis}

In this section we analyse how changes to parameters in the model impacts the results. This provides evidence that our results are robust. We consider these changes to parameters; survival probabilities, age efficiencies, and risk aversion. Within our analysis we focus on our key findings from Section 4.3; optimal taper rates under fixed and variable cost pension systems. 


\subsection{Survival Probabilities}

We consider the current Australian survival probabilities and lower survival probabilities ${ }^{6}$ as pictured in Figure 8, and explore how changes to these probabilities impact our findings.

Figure 8: Conditional Survival Probabilities

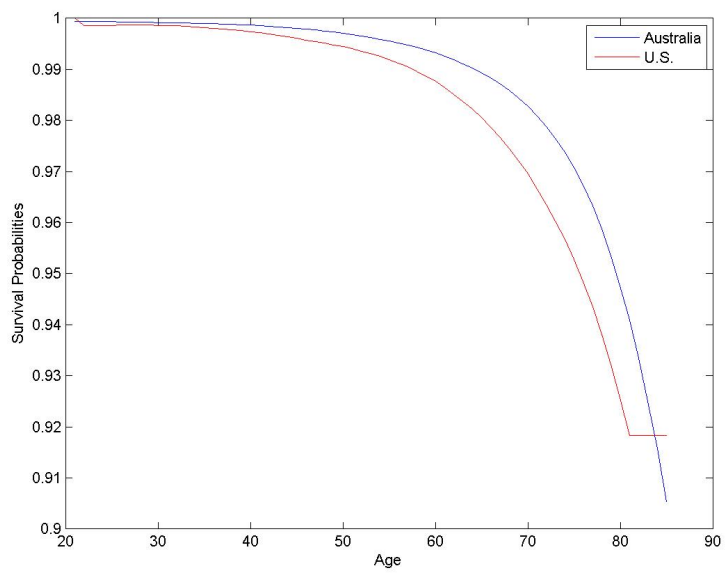

Table 5: Survival Probabilities with Changing Taper Rates

\begin{tabular}{|c|c|c|c|c|c|c|}
\hline \multirow[b]{2}{*}{ Taper Rate } & \multicolumn{3}{|c|}{ High survival rates } & \multicolumn{3}{|c|}{ Low survival rates } \\
\hline & $\mathrm{CEV}(\%)$ & Savings & Labour & $\operatorname{CEV}(\%)$ & Savings & Labour \\
\hline \multicolumn{7}{|l|}{ Variable cost } \\
\hline 0.0 & -7.550 & 92.4 & 98.8 & -5.286 & 96.0 & 101.5 \\
\hline 0.25 & -1.969 & 98.5 & 100.4 & -3.724 & 96.8 & 101.0 \\
\hline 0.5 & 0.000 & 100.0 & 100.0 & 0.000 & 100.0 & 100.0 \\
\hline 0.75 & 6.661 & 107.4 & 98.3 & 3.891 & 103.3 & 98.9 \\
\hline 1.0 & 9.597 & 110.6 & 97.7 & 7.652 & 106.5 & 97.9 \\
\hline \multicolumn{7}{|l|}{ Fixed cost } \\
\hline 0.0 & 0.697 & 100.6 & 99.8 & 0.866 & 100.4 & 99.8 \\
\hline 0.25 & 0.338 & 100.0 & 100.0 & 0.422 & 100.4 & 99.9 \\
\hline 0.5 & 0.000 & 100.0 & 100.0 & 0.000 & 100.0 & 100.0 \\
\hline 0.75 & -0.083 & 99.8 & 100.1 & -0.101 & 99.9 & 100.0 \\
\hline 1.0 & -0.292 & 99.6 & 100.1 & -0.258 & 99.9 & 100.1 \\
\hline
\end{tabular}

We can see from our results in Table 5 that survival probabilities have an impact on savings behaviour and welfare under a means-tested pension system. However, the results align with our findings in Section 4 in that a taper rate of 1.0 produces the largest welfare gain in a variable cost model due to lower tax rates. Under a fixed cost model we can see that a universal benefit provides the best welfare outcome, which aligns with our results from Section 4.3.

\footnotetext{
${ }^{6}$ For the lower survival probabilities we use U.S. values as used by Huggett \& Parra (2010)
} 


\subsection{Age Efficiency Profiles}

We consider the current flat efficiency profile used in Australia and a more concave age efficiency profile $^{7}$ shown in Figure 9. We examine if the distribution of age efficiency impact our findings, focusing on how larger differences in potential earnings across age groups impact welfare and savings.

Figure 9: Age Efficiency Profile

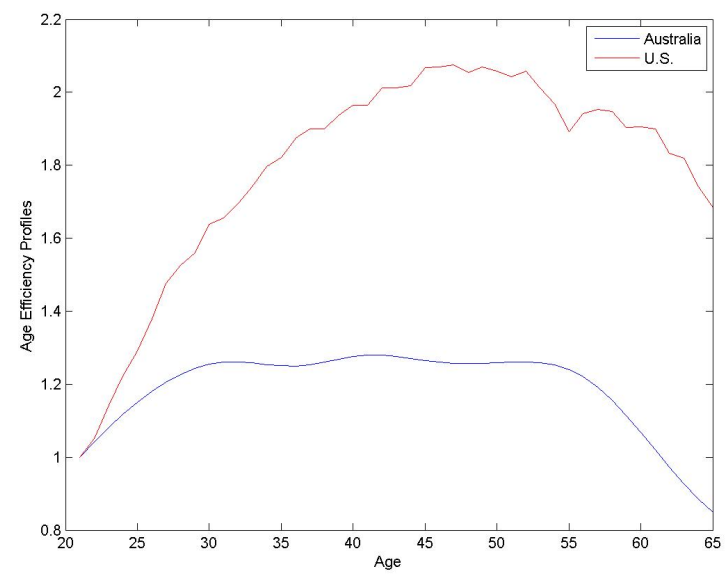

Table 6: Age Efficiencies with Changing Taper Rates

\begin{tabular}{|c|c|c|c|c|c|c|}
\hline \multirow[b]{2}{*}{ Taper Rate } & \multicolumn{3}{|c|}{ Flat distribution } & \multicolumn{3}{|c|}{ Concave distribution. } \\
\hline & $\operatorname{CEV}(\%)$ & Savings & Labour & $\operatorname{CEV}(\%)$ & Savings & Labour \\
\hline \multicolumn{7}{|l|}{ Variable cost } \\
\hline 0.0 & -7.550 & 92.4 & 98.8 & -7.215 & 92.8 & 102.1 \\
\hline 0.25 & -1.969 & 98.5 & 100.4 & -3.847 & 95.7 & 101.1 \\
\hline 0.5 & 0.000 & 100.0 & 100.0 & 0.000 & 100.0 & 100.0 \\
\hline 0.75 & 6.661 & 107.4 & 98.3 & 2.140 & 99.9 & 99.5 \\
\hline 1.0 & 9.597 & 110.6 & 97.7 & 3.383 & 101.4 & 99.1 \\
\hline \multicolumn{7}{|l|}{ Fixed cost } \\
\hline 0.0 & 0.697 & 100.6 & 99.8 & 0.630 & 100.8 & 99.8 \\
\hline (\%) 0.25 & 0.338 & 100.0 & 100.0 & 0.178 & 100.2 & 99.9 \\
\hline 0.5 & 0.000 & 100.0 & 100.0 & 0.000 & 100.0 & 100.0 \\
\hline 0.75 & -0.083 & 99.8 & 100.1 & -0.201 & 99.9 & 100.1 \\
\hline 1.0 & -0.292 & 99.6 & 100.1 & -0.525 & 99.8 & 100.2 \\
\hline
\end{tabular}

Table 6 results show that under a variable cost programme with a concave distribution of age efficiencies, a taper rate of 1.0 produces the largest welfare gain. This result aligns with our conclusion in Section 4, indicating that while the distribution of age efficiencies will impact the magnitude of the welfare gain, it will not change the directional impact a change in the taper rate produces.

We can also see from Table 6, that the welfare gains from changing taper rates under a variable cost programme with a concave distribution of age efficiencies are optimised for a universal benefit

\footnotetext{
${ }^{7}$ For the concave age efficiency profile we use data on the U.S. as reported by Huggett \& Parra (2010)
} 
under a fixed cost model. Again, this is due to the fact that the welfare gains under from increasing taper rates under a variable cost programme are due to lower tax, not better distribution of benefits.

We conclude that while different age efficiency profiles do impact the size of the welfare gain and changes in individuals labour supply behaviour under different taper rates within a meanstested pension system, the results are similar to those in Section 4. Our results come to the same conclusion as Section 4, that welfare gains under a variable cost programme are not present under a fixed cost model.

\subsection{Risk Aversion}

In this section we use a higher risk aversion parameter of 3 and explore whether this impacts our results. A higher risk aversion parameter is representative of a more risk averse economy.

Table 7: Risk Aversion with Changing Taper Rates

\begin{tabular}{cccccc}
\hline \hline Taper Rate & Benefit & Cost & CEV (\%) & Savings & Labour \\
\hline Variable cost & & & & & \\
\hline 0.0 & 15,000 & -2.07 & -8.433 & 94.3 & 102.1 \\
0.25 & 15,000 & -1.91 & -3.982 & 97.4 & 101.0 \\
$\mathbf{0 . 5}$ & $\mathbf{1 5 , 0 0 0}$ & $\mathbf{- 1 . 6 5}$ & $\mathbf{0 . 0 0 0}$ & $\mathbf{1 0 0 . 0}$ & $\mathbf{1 0 0 . 0}$ \\
0.75 & 15,000 & -1.38 & 6.445 & 105.1 & 98.65 \\
1.0 & 15,000 & -1.22 & 15.548 & 111.5 & 96.8 \\
\hline Fixed cost & & & & & \\
\hline 0.0 & 9,000 & -1.65 & 0.915 & 100.6 & 99.8 \\
0.25 & 12,000 & -1.65 & 0.395 & 100.2 & 99.9 \\
$\mathbf{0 . 5}$ & $\mathbf{1 5 , 0 0 0}$ & $\mathbf{- 1 . 6 5}$ & $\mathbf{0 . 0 0 0}$ & $\mathbf{1 0 0 . 0}$ & $\mathbf{1 0 0 . 0}$ \\
0.75 & 16,000 & -1.65 & -0.154 & 100.0 & 100.0 \\
1.0 & 18,000 & -1.65 & -0.551 & 99.6 & 100.2 \\
\hline
\end{tabular}

Table 7 illustrates that in an economy with a higher risk aversion parameter, the results from Section 4 still hold; a taper rate of 1.0 maximises welfare under a variable cost pension system and a universal benefit maximises welfare under a fixed cost system.

\section{Conclusion}

Pension programmes play an important role in society by providing insurance against longevity risk. However, these pension programmes can distort labour supply and savings behaviour of individuals, resulting in welfare losses. In this paper we explore how changes to the current Australian pension system impact welfare.

The design of pension systems is a topic of many recent studies given their role in society. Our work builds on that by Kumru \& Piggott (2009), using an overlapping-generations model to explore changes in savings and labour behaviour in response to changes in the means-tested taper rate. We also examine welfare differences between an economy with no pension system, and that with either 
a PAYG system or means-tested system.

Previous research has focused on changes to taper rates within the means-tested pension programme and the resulting change in welfare. However, there has been little consideration to how the change in the programme cost interplays with the change in welfare. Our work extends on the current body of research by changing both the taper rate and benefit payment to hold the cost of the programme constant, and then considering the impact on welfare.

We find, similar to Auerbach \& Kotlikoff (1987) and Tran \& Woodland (2011), that a meanstested system is welfare reducing. However, a means-tested system does provide a welfare gain compared to a similar costing PAYG system. We also find that, similar to previous work by Kumru \& Piggott (2009) and Tran \& Woodland (2011), a taper rate of 1.0 provides the best welfare outcome in a pension system with fixed benefit and variable cost. However, when we hold the cost of the programme constant, we find an opposing impact on welfare, with a universal benefit providing the maximum welfare. This is due to the fact that under a variable cost system lower taper rates result in higher costs, and these costs are financed through taxation of individuals during their working life which drives the welfare losses. Once the cost for the system is held constant, we see that lower benefits paid to all individuals provides the best welfare outcome.

Our model assumes evenly distributed income through the wage rate shocks. Given the results from our sensitivity analysis on age efficiency profiles, we would suggest that exploration of varying shock distribution would provide an interesting extension on our work. We also consider inclusion of superannuation and endogenous retirement decision would be beneficial in future research. Finally, our model assumes constant population age distribution. Give that there is growing pressure on government financing of aged pension from an ageing population, inclusion of this phenomenon would provide an interesting extension to our work. 


\section{References}

[1] Auerbach, A. J., \& Kotlikoff, L. J. 1987. Dynamic Fiscal Policy. New York, NY, USA: Cambridge University Press.

[2] Buddelmeyer, H., Lee, W. S., Wooden, M. \& Vu, H. 2007. Low Pay Dynamics: Do LowPaid Jobs Lead to Increased Earnings and Lower Welfare Dependency Over Time. Melbourne Institute of Applied Economic and Social Research

[3] Cho, S.W., \& Sane, R. 2011. Means-tested Age Pension and Homeownership: Is There a Link? Macroeconomic Dynamics, 17, 1281 - 1310.

[4] Conesa, J. C., Kitao, S., Krueger, D. 2009. Taxing capital? Not a bad idea after all!. American Economic Review 99, 25-48.

[5] Greenville, J., Pobke, C., \& Rogers, N. 2013. Trends in the Distribution of Income in Australia. Productivity Commission Staff Working Paper

[6] Hockey J.B. Cormann, M., Budget Strategy and Outlook: Budget Paper No. 1, Budget 201415, Commonwealth of Australia, Canberra

[7] Huggett, M., \& Ventura, G. 1999. On the distributional effects of social security reform. Review of Economic Dynamics, 2, 498-531.

[8] Huggett, M., \& Parra, J. C. 2010. How Well Does the U.S. Social Insurance System Provide Social Insurance? Journal of Political Economy, 1, 76-112.

[9] Imrohoroglu, A., Imrohoroglu, S., \& Joines, D. H. 1995. A life cycly analysis of social security. Economic Theory, 6, 83-114.

[10] King, R. G., Plosser, C. I., \& Rebelo, S. 2002. Production, Growth, and Business Cycles: Technical Appendix. Computational Economics, 20, 87-116.

[11] Kudrna, G., \& Woodland, A. 2011. An Intertemporal General Equilibrium Analysis of the Australian Age Pension Means Test. Journal of Macroeconomics 33, 61-79.

[12] Kumru, C., \& Piggott, J. 2009. Should Public Retirement Provision Be Means-tested? ABS Research Paper No. 2009 AIPAR 01.

[13] Kumru, C., \& Thanopoulos, A. C. 2011. Social security reform with self-control preferences. Journal of Public Economics 95, 886-899.

[14] Sefton, J., \& van de Ven, J. 2009. Optimal design of means-tested retirement benefits. The Economic Journal, 119, 461-481.

[15] Tauchen, G., \& Hussey, R. 1991. Quadratic-Based Methods for Obtaining Approximate Solutions to Nonlinear Asset Pricing Models. Econometrica 59, 371-396

[16] Tran, C., \& Woodland, A. 2014. Trade-Offs in Means Tested Pension Design. Journal of Economic Dynamics adn Control 47, 72-93. 